\title{
The resource-saving technology to restore the accumulation ability of tailing ponds
}

\author{
Olha Medvedieva ${ }^{1, *}$, Yevhen Lapshyn ${ }^{1}$, Natalia $\mathrm{Koval}^{1}$, Abdikarim Zeynullin ${ }^{2}$, and Olena \\ Gupalo ${ }^{1,3}$ \\ ${ }^{1}$ Institute of Geotechnical Mechanics named by N. Poljakov of National Academy of Sciences of \\ Ukraine, 49005, Dnipro, Simferopolska Str., 2a, Ukraine \\ ${ }^{2}$ Kazakhstan National Academy of Natural Science, Z01G3M1 (010000), Nur-Sultan, Koshkarbayev \\ Ave., 26/20, Kazakhstan \\ ${ }^{3}$ National Metallurgical Academy of Ukraine, 49600, Dnipro, Haharina Ave., 4, Ukraine
}

\begin{abstract}
The accumulating capacity of tailing ponds by technology infusion of pulp preliminary clarification in the alluvium charts with its subsequent thickening and storage in the form of a highly concentrated pulp at the bottom of the pond is proposed by authors in the work. For the first time, the time dependence of filling a temporary pond on the ratio of the initial and condensed slurry concentrations for such technologies is obtained. The formula for calculating the degree of condensation is proposed. It provides the parameters selection and justification of equipment for removing water from a temporary pond as the map is filled with the accumulating capacity restoration of tailing ponds. The calculation results for the proposed dependencies allow us to establish: the necessary values of the thickening degree of the hydromixture, the possible intervals of the change in the pulp flow before and after thickening, as well as the volume of water taken from the temporary pond, depending on the concentration of the slurry entering the pond from the alluvium maps, its volumetric flow rate, geometric parameters of the technology for waste storage and the operation duration of a temporary pond.
\end{abstract}

\section{Introduction}

Kryvyi Rih Iron Ore Basin is the largest in Ukraine, where more than $80 \%$ of iron ore is mined and more than $20 \%$ of metallurgical product is produced. The main enterprises of the mining industry are concentrated in the Basin: five largest mining and processing plants (MPP) with ten quarries which are deeper than $300 \mathrm{~m}$ and 17 mines with a depth of $80-$ $1300 \mathrm{~m}$ for mining of iron ore. Each of these facilities has its own tailing ponds (TP) for mining and processing, which are considered by many experts as technogenic deposits of iron ores various types and related non-metallic minerals $[5,6]$.

Currently, according to various estimates, the Kryvbas dumps contain up to 13 billion tons of overburden rocks, and tailing ponds contain up to 6 billion tons of products after processing mineral raw materials [1-4], which occupy more than 10 thousand ha [4-8].

\footnotetext{
*Corresponding author: medvedevaolga1702@gmail.com
} 
These resources are increasingly attracted by their ability to be used both for obtaining concentrates of mineral raw materials and for freeing up space for storage of new waste, which is not available in Kryvbas [2, 3, 6-9]. Thus mines, quarries and tailing ponds are located throughout the city of Kryvyi Rih and its neighboring areas, where the free land for storing mineral processing products is not available.

The world experience in the TP operation indicates the following solutions to the problem: waste storage in the slurry form with a hydromixture paste concentration; flood walls building up; the intensification process of water clarification in the pond using flocculants and coagulants; the mode choice of washing cards; the dusting surface parameters changing of surface and underwater alluviums; separate storage introduction of solid phase fractions; preliminary clarification of the pulp in the alluvium maps before entering the pond.

The use of paste thickeners in the conditions of Krivbas MPP is not possible due to the large length of the transport lines and significant differences in geodetic heights (Table 1). These technologies are usually introduced at new TP, where waste management is carried out on the first tier [9].

Table 1. Parameters of TP of the Kryvbas MPP.

\begin{tabular}{|l|c|c|c|c|}
\hline \multicolumn{1}{|c|}{ Name of TP } & $\begin{array}{c}\text { Height of } \\
\text { dikes, } \mathrm{m}\end{array}$ & $\begin{array}{c}\text { Area, } \\
\text { hectare }\end{array}$ & $\begin{array}{c}\text { Volume } \\
\cdot 10^{6}, \mathrm{~m}^{3}\end{array}$ & $\begin{array}{c}\text { Annual volume } \\
\text { of refuse } \cdot 10^{6}, \mathrm{~m}^{3}\end{array}$ \\
\hline $\begin{array}{l}\text { TP "Voikove" of } \\
\text { Pivdennyi MPP }\end{array}$ & $\begin{array}{c}\text { from } 50 \\
\text { to } 74\end{array}$ & 250 & 156.5 & 11.50 \\
\hline $\begin{array}{l}\text { TP "Obiednane" of } \\
\text { Pivdennyi MPP and } \\
\text { ArselorMittall }\end{array}$ & $\begin{array}{c}\text { from } 40 \\
\text { to } 59\end{array}$ & $\begin{array}{c}\text { from } 350 \\
\text { to } 550\end{array}$ & 320.0 & 6.50 \\
\hline $\begin{array}{l}\text { TP "Myroliubivske" of } \\
\text { ArselorMittall }\end{array}$ & 55 & 324 & 107.0 & 10.60 \\
\hline TP of Inhuletskyi MPP & 112 & - & 379.0 & 4.52 \\
\hline TP of Tsentralnyi MPP & 10 & - & 290.0 & 7.00 \\
\hline TP of Pivnichnyi MPP & 76 & 1750 & 466.0 & 8.84 \\
\hline $\begin{array}{l}\text { TP of No. 2 of V.A. } \\
\text { Valiavko Mine CPP, } \\
\text { "Pivnichnyi" }\end{array}$ & 10 & 300 & 210.0 & not in operation \\
\hline
\end{tabular}

The intensification of the clarification process of water in the pond by adding the TP enables to precipitate the solid particles much faster, however, it worsens the properties of the resulting sediment deposition. As a result of flocculi formation, such a sediment will be loose, more voluminous, and less reliable in terms of the retaining dikes stability [10 - 16]. Managing the parameters of the mode for hydraulic filling the maps and changing the parameters of the dusting surface of surface and underwater alluviation involve the use of cost-intensive technologies for pulp thickening before storage or means for regulating the operation mode of the hydraulic transportation complex. The introduction of the separate storage of solid phase fractions involves a substantial modernization of the entire system of storage and transportation of rock refuse.

The preliminary clarification of the pulp in the alluvial maps before entering the pond is a method that is rarely used in domestic mining and processing plants (Fig. 1). Idea of this method is based on the peculiarity of the map alluviation technology: the pond is separated from the alluviation map by a protecting dike, near the internal slope of which, as a result of hydraulic filling the map, a local pond is formed, which is used until pulp is fed to dusting surfaces of the bench. After hydraulic filling the map in the protecting dike, the outlets are made and the local pond contents enter the storage pond for clarification (Figure 1). This 
technology is not effective at the final stages of TP operation, when the storage pond dimensions do not provide clarification of even previously settled hydromixtures.

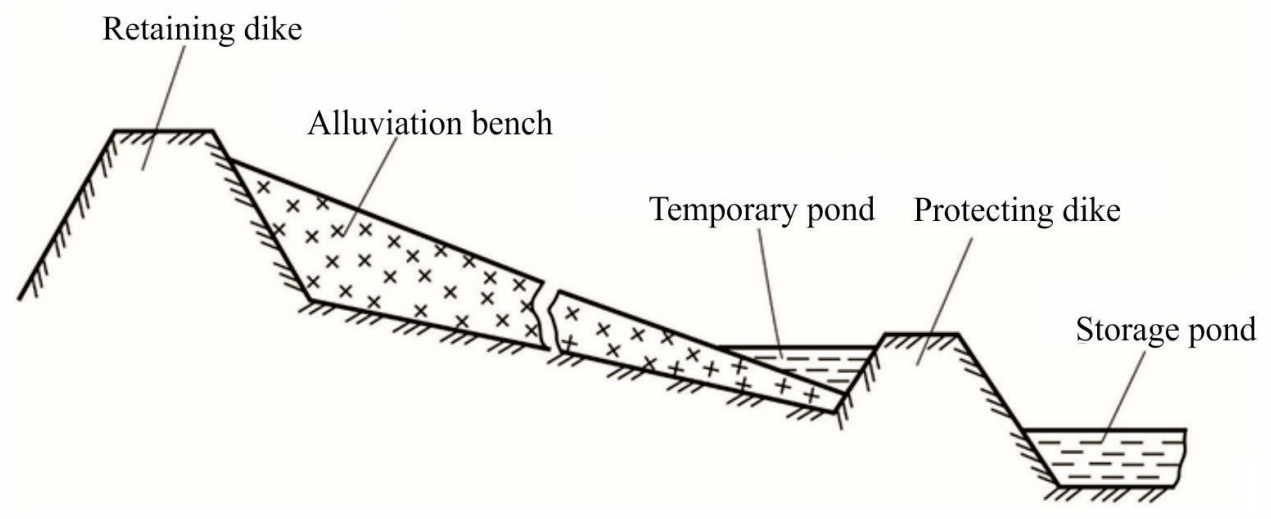

Fig. 1. The known technology to store the rock refuse using a temporary pond in a map with subsequent water discharge into the pond.

Therefore, all MPP in Kryvbas are forced to use the only known technology for increasing the accumulating ability - to build up dams. This will create new containers for enrichment waste, but will reduce the geometric dimensions of the storage pond, and it is inability threat to clarify recycled water to the required quality. In the near future, this factor will make it impossible for them to have an extensive development path by additionally attracting volumes of recycled water, expanding the area and building new TP. The most effective way out of this situation is the transition to an intensive development path, when a place for new volumes of enrichment waste will be provided through more efficient use of existing tanks, the clarification process intensification of recycled water and associated extraction of the remaining mineral deposit.

Such a radical technologies changing for storing waste enrichment and operation of waste storage requires preliminary justification. Videlicet: possible volumes estimates of clarified circulating water, the required volumes for storing the condensed slurry, as well as the released volumes of the storage available for storing new enrichment waste. Thus, the aim of the study is to assess the possible distribution of water, slurry and particulate consumption during preliminary clarification of the pulp containing clay and dust fractions in the temporary pond depending on the degree of thickening, geometric parameters of the waste storage technology and the operation continuance of the temporary pond.

\section{Methodology}

At the final stage of TP operation, when the storage capacity of TP is small, the slurry emanating from the proran will not have time to clarify in the illuminator pond due to its small geometric dimensions. For restoring of the TP accumulating ability, the authors of the work propose to improve the well-known technology of preliminary clarification of pulp in the alluvium maps. The modernization is in not using openings for diverting the slurry into the clarifier pond, but in directing the pulp from the local pond to thicken. This will make it possible to store already condensed highly concentrated pulp at the bottom of the pond without interference for the clarification process, and to supply water to the circulating water supply system (Fig. 2).

To implement the idea proposed in the work, the specialized partitions can be used that prevent entering the solid particles into the pond, thickeners for separating dusty, chalky 
and clay fractions, processing the pulp with permanent magnets. Partitions are set instead of the protecting dike or in its outlets, providing filtering of liquid entering the pond from solid particles.

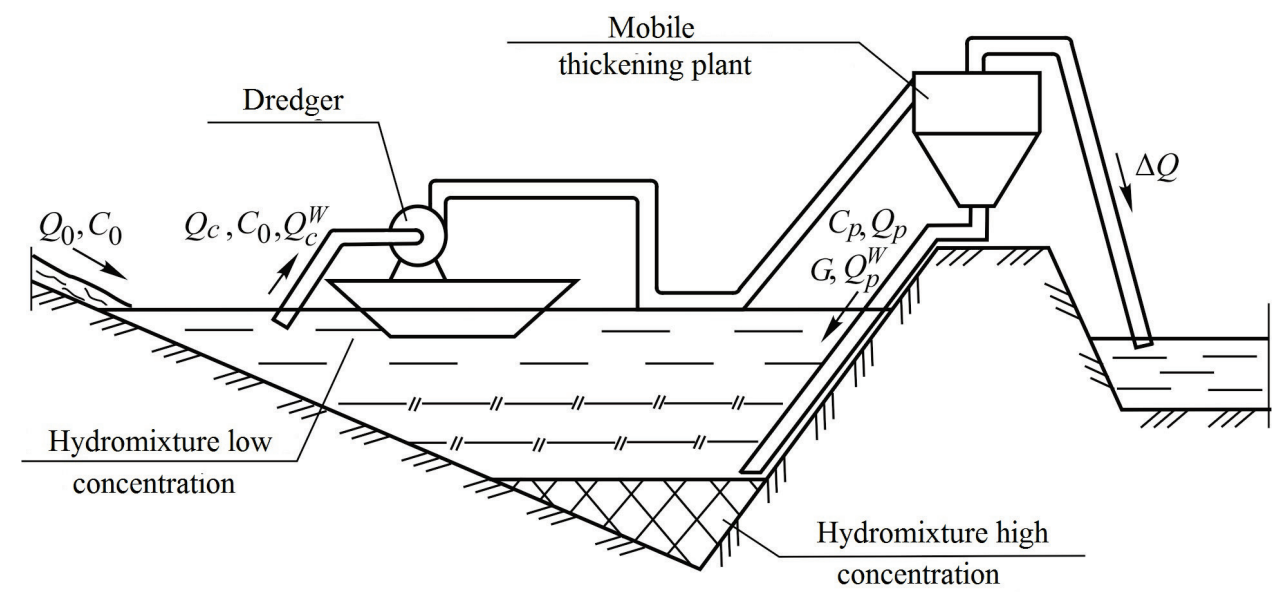

Fig. 2. A promising method for removing a temporary pond after filling the map, providing restoration of the accumulation ability of the tailing pond: $Q_{0}$ - volumetric flow rate of low concentration pulp according to alluvium maps, $\mathrm{m}^{3} / \mathrm{s} ; Q_{p}$ - the pulp volumetric flow rate with the concentration of the paste entering the lower part of the temporary pond, $\mathrm{m}^{3} / \mathrm{s} ; Q_{c}$ - pulp volumetric flow rate of low concentration taken from the pond, $\mathrm{m}^{3} / \mathrm{s} ; C_{p}$ - hydromixture concentration, entering the lower part of the temporary pond; $C_{0}$ - hydromixture concentration entering the pond from alluvium maps; $Q_{c}{ }^{w}$ - volumetric flow rate of water from a temporary pond, $\mathrm{m}^{3} / \mathrm{s} ; Q_{p}{ }^{w}$ - volumetric flow rate of water entering the temporary pond together with highly concentrated cellulose, $\mathrm{m}^{3} / \mathrm{s} ; G-$ the circulating volume of solid particles between the temporary pond and the thickener, $\mathrm{m}^{3} / \mathrm{s} ; \Delta Q-$ difference between the volumetric flow rates of water entering the pond and discharged from the pond, $\mathrm{m}^{3} / \mathrm{s}$.

One of the variants for restoring the accumulation ability of the tailing pond is to preliminary clarify the pulp containing clay and dusty fractions in the temporary pond by supplying weak solutions of reagents, coagulation and flocculation agents. The obtained clarified water and loose sediment are consequently sent into the circulating water supply system and to the core of the tailing pond. The sediment friableness is eliminated by passing it through the centrifugal pump in the form of a pulp with a paste concentration. The centrifugal pump, in this case, acts as a disintegrator of flakes and flocculi, which makes the highly concentrated pulp more homogeneous, and the sediment during its storage is denser. However, the temporary pond has a significant free surface area exposed to wind, which makes it difficult to evenly distribute the reagents.

Therefore, the most potential will be a hydraulic mixture dredger intake with subsequent thickening of its mobile thickening installation (Fig. 2). In this case, to assess the possible distribution of the water flow rates, hydromixture and solid particles during preliminary pulp clarification in a temporary pond, the conditions for maintaining the volume of the hydromixture, as well as its liquid and solid phases are considered. Assuming that the hydromixture volume of the low concentration taken from the temporary pond is divided by the corresponding volume of the high concentration hydromixture that is returned to the temporary pond and the volume of clarified process water that is sent to the recycled water supply system. The requirements of the technology for storing enrichment waste, which consists in the fact that the level of the mirror in the temporary pond should not be changed, will also be taken into account $[9$, $10]$. Given the continuity of the technological process, we assume that the concentration 
of the hydromixture that enters the pond from the alluvium map and the hydromixture selected from the pond are the same. Taking into account the accepted assumptions, the reckoning of the pulp preliminary clarification process conditions in a temporary pond can be used next associations (1-4):

$$
\begin{gathered}
Q_{C}=K_{C} Q_{0}, \quad Q_{P}=K_{P} Q_{0}, \quad Q_{C}^{W}=w_{C} Q_{0}, \quad Q_{P}^{W}=w_{P} Q_{0}, \\
G=K_{g} Q_{0}, \quad \Delta Q=K_{q} Q_{0}, \\
K_{P}=\frac{1}{c-1}, \quad K_{C}=\frac{c}{c-1}, \quad w_{c}=\frac{1-C_{0} c}{c-1} c, \\
w_{p}=\frac{1-C_{0} c}{c-1}, \quad K_{g}=\frac{c C_{0}}{c-1}, \quad K_{q}=1-C_{0} c, \quad c=\frac{C_{P}}{C_{0}},
\end{gathered}
$$

where $K_{p}$ - pulp mass ratio after thickening; $K_{c}$ - pulp mass ratio before thickening; $w_{c}-$ water mass ratio befor thickening; $w_{p}$ - mass ratio after thickening; $K_{g}$ - mass ratio soot; $K_{q}$ - mass ratio water break free; $c$ - hydromixture thickening level.

Formulas (1) and (4) allow to estimate the total flow rate of pulp, water and particulate matter for a temporary pond, which provides a justification of the equipment parameters for the technology in question, depending on the hydromixture thickening level. The same formulas allow to write the right-hand sides of the equations describing the change in the heights of the water levels and solid particles in a temporary pond:

$$
\frac{d W_{s}}{d t}=C_{0} Q_{0}-C_{0} K_{C} Q_{0}+K_{g} Q_{0}, \quad \frac{d W_{f}}{d t}=\left(1-C_{0}\right) Q_{0}-w_{C} Q_{0}+w_{P} Q_{0},
$$

which, taking into account formulas (1) and (4) and expressions for calculating the volumes of hydromixtire low concentration and solid particles accumulated in a temporary pond (Fig. 3)

$$
W_{s}=C_{p} C_{\beta \varphi} \frac{h_{s}^{2}}{2} L, \quad W_{f}=C_{\beta \varphi} \frac{\left(h_{f}-h_{s}\right)^{2}}{2} L+\left(1-C_{p}\right) C_{\beta \varphi} \frac{h_{s}^{2}}{2} L, \quad C_{\beta \varphi}=\operatorname{ctg} \beta+\operatorname{ctg} \varphi,
$$

are transposed to the next form:

$$
\begin{gathered}
\eta_{s} \frac{d \eta_{s}}{d \tau}=\frac{1}{c}, \quad \eta_{s}(\tau=0)=0, \\
\left(\eta_{f}-\eta_{s}\right) \frac{d \eta_{f}}{d \tau}+\left(\eta_{s}\left(2-C_{p}\right)-\eta_{f}\right) \frac{d \eta_{s}}{d \tau}=(c-1) C_{0}, \quad \eta_{f}(\tau=0)=0, \\
\eta_{s}=\frac{h_{s}}{H}, \quad \eta_{f}=\frac{h_{f}}{H}, \quad \tau=\frac{Q_{0} t}{C_{\beta \varphi} H^{2} L},
\end{gathered}
$$

where $W_{s}-$ volume of solid particles accumulated in the temporary pond, $\mathrm{m}^{3}$; $W_{f}$ - hydromixture volume of low concentration accumulated in the temporary pond, $\mathrm{m}^{3}$; $t$ - time, s; $h_{s}$ - bed depth of the solid particles, $\mathrm{m} ; h_{f}$ - hydromixture bed depth of low concentration above bed solid particles, $\mathrm{m}$; $L$ - length of alluvial front, $\mathrm{m}$; $\beta$ - beach angle to the horizon, deg.; $\varphi-$ the internal angle of the slope to the 
horizontal temporary dam, deg.; $\eta_{s}-$ relative height of the bed solid particles; $\tau$ - nondimensional time; $\eta_{f}-$ relative height of the hydromixture bed low concentration above the bed solid particles; $H$ - height of the temporary dam counted from the internal slope, $\mathrm{m}$.

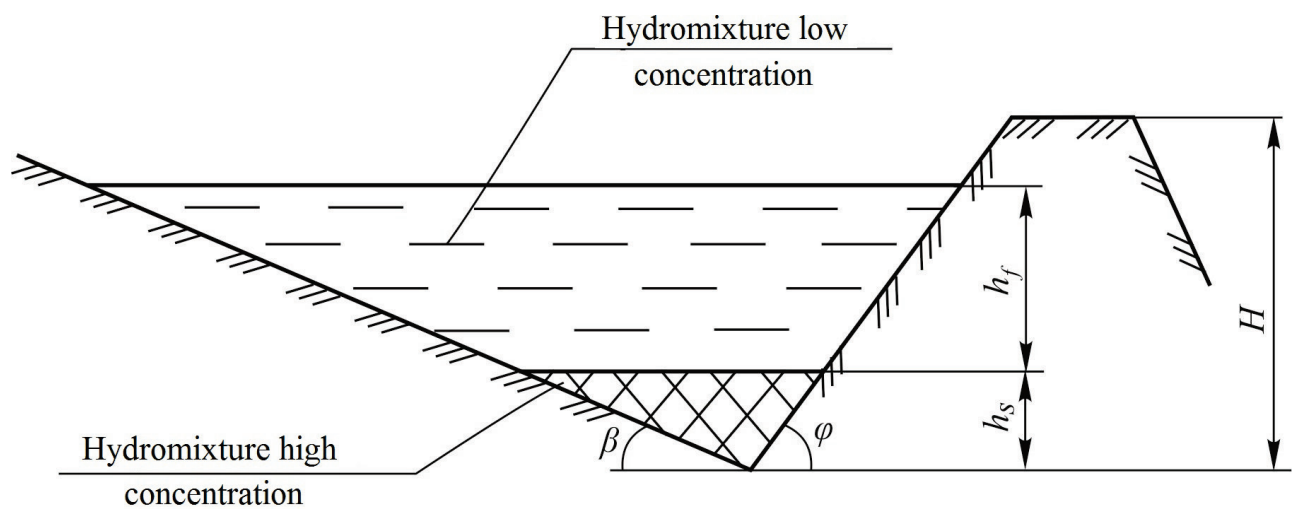

Fig. 3. To the calculation of volumes hydromixture low concentration and solid particles accumulated in a temporary pond.

Equation (5) under the initial condition under consideration is easily solvable in quadratures

$$
\eta_{s}(\tau)=\sqrt{\frac{2}{c} \tau},
$$

and equation (6), after the next change of variable

$$
z=\sqrt{\frac{2}{c} \tau},
$$

reduced to a form allowing separation of variables with subsequent integration

$$
\frac{d\left(0.5 \eta_{f}^{2}-z \eta_{f}\right)}{d z}=\left[(c-2) c C_{0}-2\right] z .
$$

The solution of the equation (10) under homogeneous initial conditions, after returning to the original variables, has the form:

$$
\eta_{f}(\tau)=\left[1+\sqrt{(c-2) c C_{0}-1}\right] \sqrt{\frac{2}{c} \tau},
$$

and is considered for the values of thickening level satisfying the inequality:

$$
\begin{gathered}
c \geq c^{\prime}, \\
c^{\prime}=\sqrt{1+\frac{1}{C_{0}}}-1,
\end{gathered}
$$

where $c^{\prime}$ - minimum permissible value of thickening level. 
Operation of the temporary pond will be stopped when the low concentration slurry reaches the upper shelf of the temporary dam:

$$
\eta_{f}\left(\tau_{H}\right)+\eta_{s}\left(\tau_{H}\right)=1
$$

where $\tau_{H}$-dimensionless operating time of a temporary pond.

Substituting formulas (8) and (11) into expression (13), after appropriate transformations, we obtain the following dependence for calculating the operation continuance of a temporary pond:

$$
\tau_{H}=\frac{0.5 c}{\left(2+\sqrt{c(c-2) C_{0}-1}\right)^{2}} .
$$

Dependence (15) allows us to evaluate the effect of the hydromixture thickening level on the operation continuance of the temporary pond. According to the results of calculations in the characteristic range of variation of the values of $c$ and $C_{0}$, formula (15) allows one to choose the values of these parameters that satisfy the requirements for the operation of the enrichment waste storage. Knowing the values of $c$ and $C_{0}$, it is possible to determine the value of the relative costs according to formulas (1) - (4). Knowing the relative flow rates, that means, determined the possible distribution of flows in the hydraulic system under consideration, using formulas (1) it becomes possible for the required volumetric flow rate of low concentration pulp coming from the alluvium maps to calculate the volumetric flow rates of water and hydraulic mixtures coming and taken from the temporary pond. This ensures the equipment selection and justification of for the implementation of the proposed technology, taking into account the parameters of the temporary pond. The accumulating capacity recovery level of the enrichment waste storage facility is estimated by the value of the circulating volume of solid particles between the temporary pond and the thickener, as well as by the difference between the volumetric flow rates of water entering the pond and discharged from the pond, which are determined by formulas (2).

\section{Results and discussion}

Dependences (3) and (4) allow to determine the relative flow rates of pulp and water before and after thickening, as well as the relative costs of the deposited particles and released water (Fig. $4-9$ ). It can be seen from formulas (15) and (7) that the degree of thickening is determined not only by the concentration of the slurry entering the pond from the alluvium maps, but also by its volumetric flow rate, as well as by the geometric parameters of the waste storage technology and the operation continuance of the temporary pond. Thus, to select the degree of condensation, it is necessary to use the dependence inverse to dependence (15) (Fig. 10), taking into account constraint (12) (Fig. 11).

Numerical results processing of the calculations by the formula (15) presented in Figure 9, indicates the possibility of approximating with accuracy satisfying engineering calculations ( $R^{2}$ from 0.960 to 0.994$)$ the degree dependence of the hydromixture thickening on the dimensionless operation continuance of the temporary pond with the following function

$$
c=\frac{0.0685}{C_{0}^{1.055}}\left[(\operatorname{ctg} \beta+\operatorname{ctg} \varphi) \frac{H^{2} L}{Q_{0} T}\right]^{2.351-5.437 C_{0}},
$$


where $T$ is the required operation continuance of the temporary pond, s.

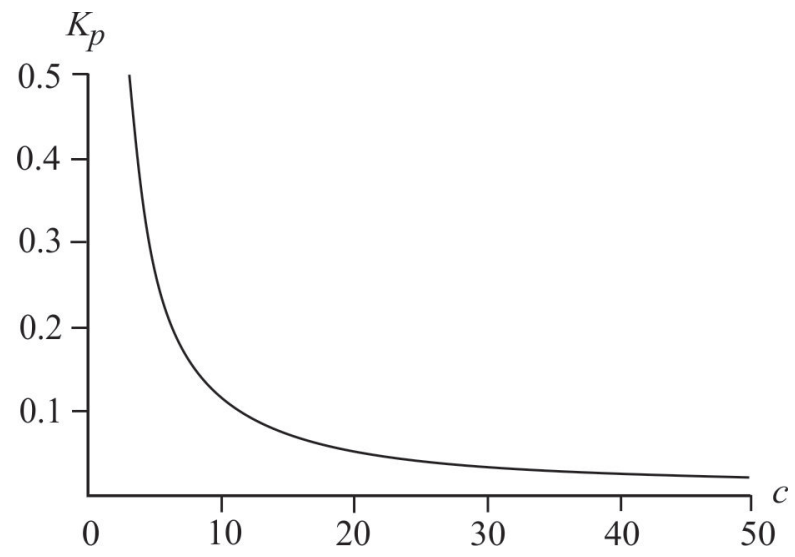

Fig. 4. Dependence of the percentage consumption of pulp after thickening on the degree of the hydraulic fluid thickening of the slurry.

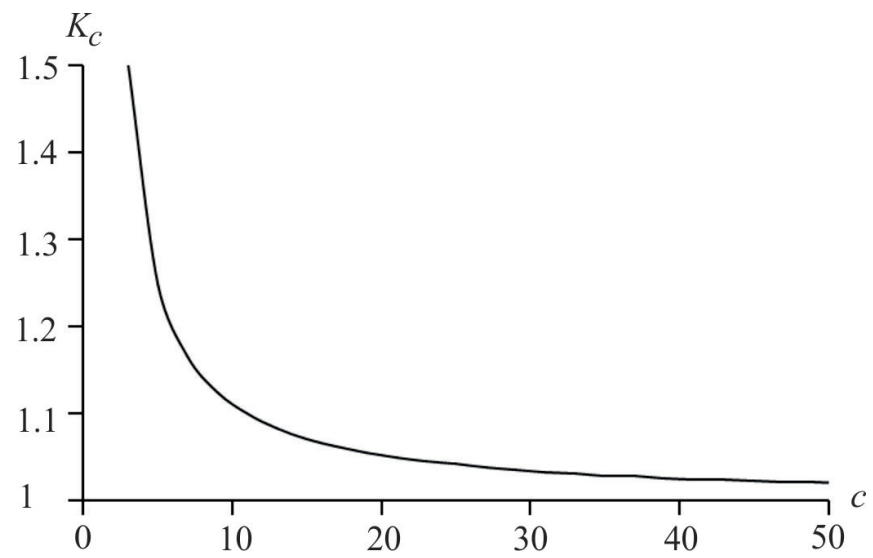

Fig. 5. Dependence of the percentage consumption of pulp before thickening on the degree of the hydraulic fluid thickening of the slurry.

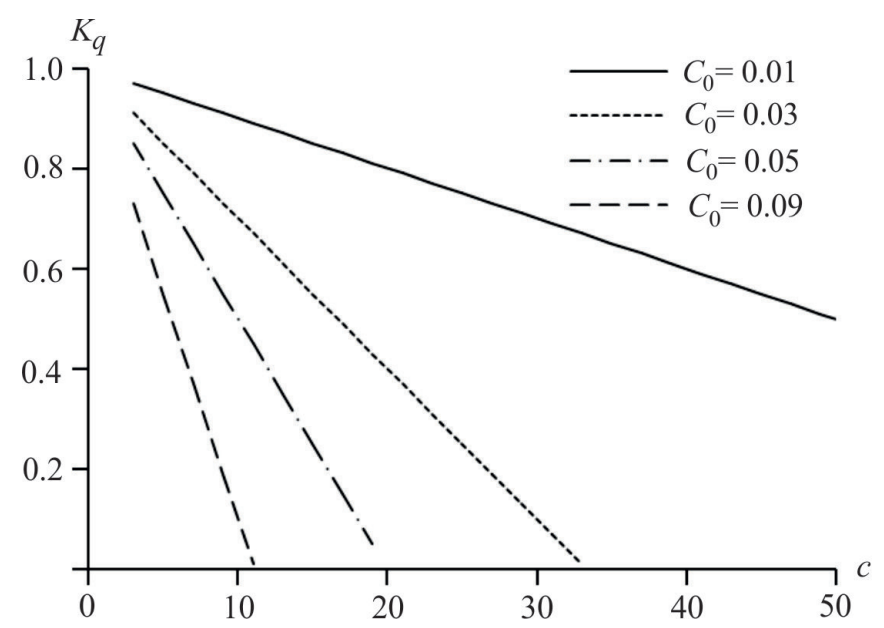

Fig. 6. Dependence of the percentage consumption of released water on the degree of the hydraulic fluid thickening at various concentrations of pulp coming from the alluvium maps. 


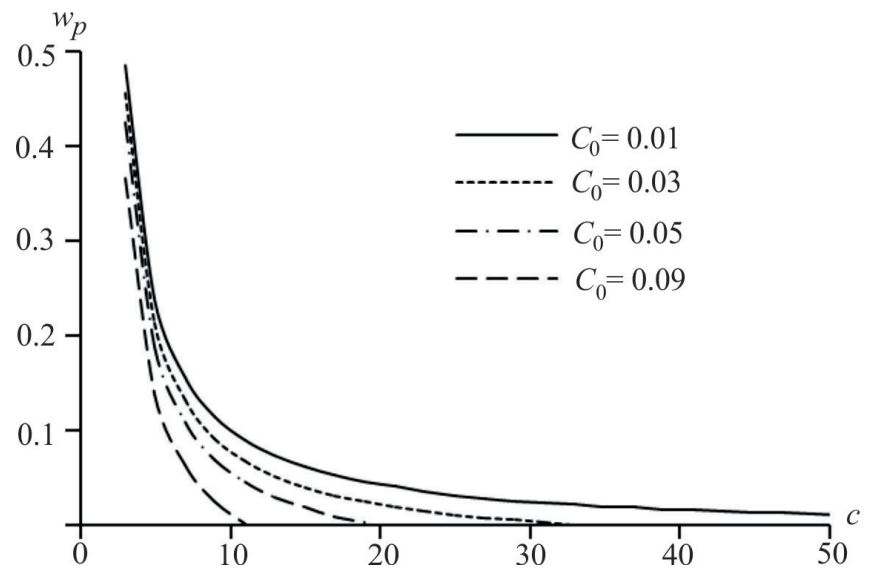

Fig. 7. Dependence of the percentage consumption of water after thickening on the degree of the hydraulic fluid thickening at various concentrations of pulp coming from the alluvium maps.

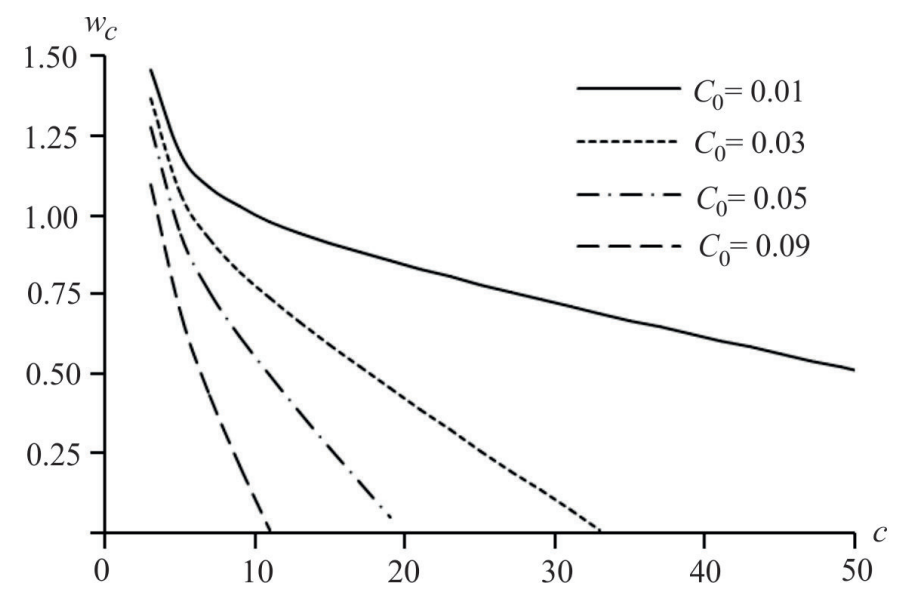

Fig. 8. Dependence of the percentage consumption of water before thickening on the degree of the hydraulic fluid thickening at various concentrations of pulp coming from the alluvium maps.

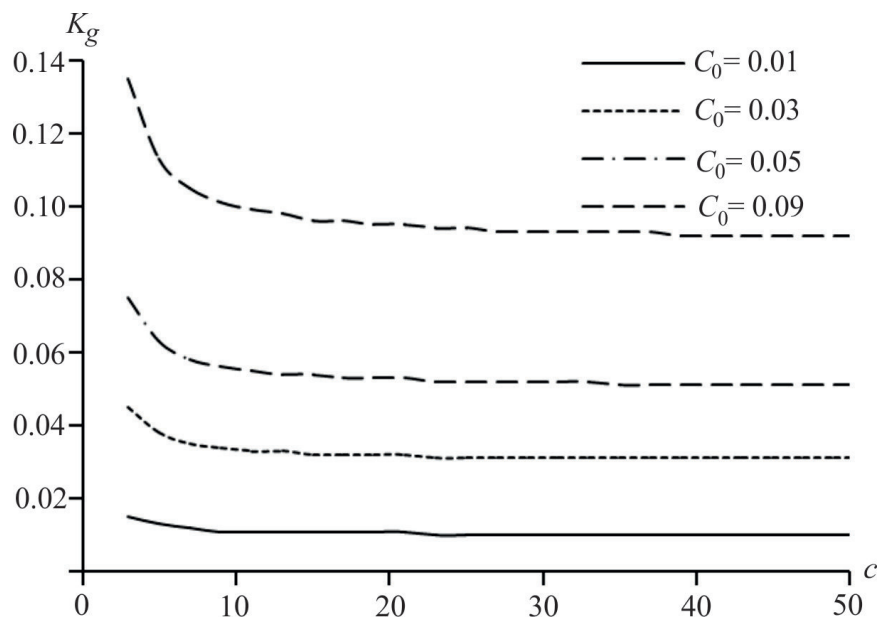

Fig. 9. Dependence of the percentage consumption of particles being precipitated on the degree of the hydraulic fluid thickening at various concentrations of pulp coming from the alluvium maps. 


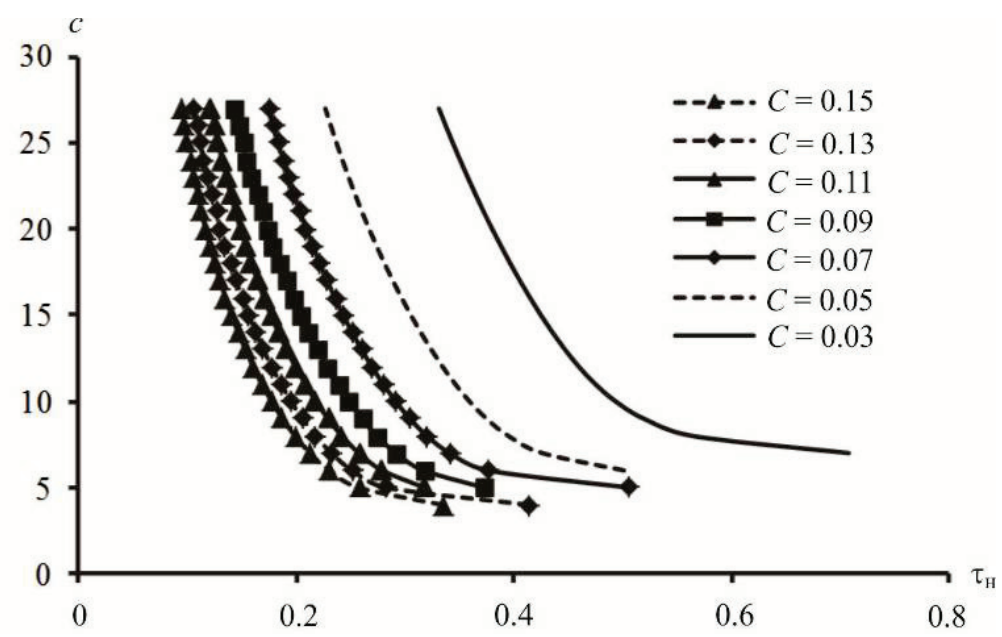

Fig. 10. The degree dependence of the hydromixture thickening on the dimensionless operation continuance of the temporary pond at different concentrations of pulp coming from the alluvium maps.

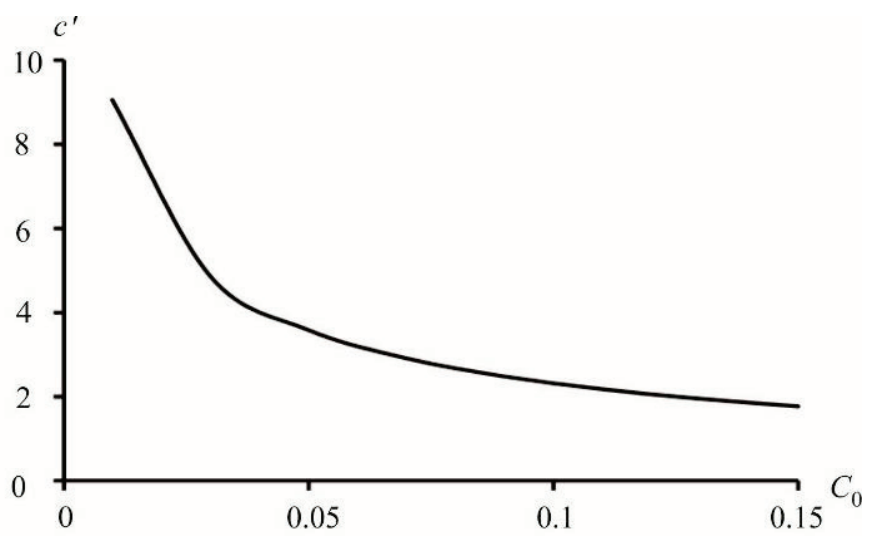

Fig. 11. The dependence of the minimum permissible degree of hydromixture thickening on the concentration of pulp coming from the alluvium maps.

Analysis of the calculation results represented in Figures $3-8$, showed that it is rational to thicken the hydromixture from the temporary pond to a degree of no more than 20. With a degree of hydromixture thickening of more than 10 , the volume of water withdrawn from the temporary pond can be comparable with the hydromixture volume entering it, since it differs from it by a maximum of $25 \%$ depending on the concentration. At the same time, the flow rate of water entering the temporary pond with the condensed hydromixture will not exceed the flow rate of its coming from the alluvium map by $10 \%$.

From Figures 9 and 10 it is seen that the degree values of the condensation from 10 to 20 provide acceptable operation of the proposed technology in the entire concentration range of the hydromixture coming from the map to the temporary pond. Moreover, with a hydromixture concentration increasing entering the thickening, the influence of the thickening degree on the filling time of the temporary pond decreases. If $\mathrm{C}_{0}=0.03$ the fractional variation in $\tau H$ does not exceed $18 \%$, then $\mathrm{C}_{0}=0.03$ it is already $28 \%$. 


\section{Conclusion}

Thus, the parameters of the technology that allow, at the final stage of TP operation the Kryvbas MPP to increase their storage capacity without building up the dams was studied. The storage capacity increasing of the TP is supposed by introducing the technology of the pulp preliminary clarification in the alluvium charts with its subsequent thickening and storage in the form of a highly concentrated pulp at the bottom of the pond without interference for the clarification process. Based on the laws of mass conservation for the temporary pond of the alluvial map the formulas are obtained that allow to estimate the total costs of the pulp, water, and solid particles for the temporary pond. For the first time for such technologies, the time dependence of filling a temporary pond on the ratio of the initial concentrations and condensed hydromixture was obtained. This allowed us to propose a formula for calculating the degree of condensation, which provides the choice and justification of equipment for removing water from a temporary pond as the map is filled with the restoration of the storage capacity of TP. The calculation results for the proposed dependencies allow us to establish the necessary values of the degree hydromixture thickening, the possible intervals for changing the flow rate of the pulp before and after thickening, as well as the volume of water taken from the temporary pond, depending on the hydromixture concentration entering the pond from the alluvium maps, its volumetric flow rate, the geometric parameters of the waste disposal technology and the operation continuance of the temporary pond.

\section{References}

1. O. Medvedeva. (2015). Development and exploitation of storages of enrichment process wastes as anthropogenic deposits. Theoretical and practical solutions of mineral resources mining. London: Taylor \& Francis Group, $567-573$

2. Anisimov, O., Symonenko, V., Cherniaiev, O., Shustov, O. (2018). Formation of safety conditions for development of deposits by open mining. E3S Web of Conferences, 60 , 00016. https://doi.org/10.1051/e3sconf/20186000016

3. Shustov, O.O., Bielov, O.P., Perkova, T.I., Adamchuk, A.A. (2018). Substantiation of the ways to use lignite concerning the integrated development of lignite deposits of Ukraine. Naukovyi Visnyk Natsionalnoho Hirnychoho Universytetu, (3), 5- 13. https://doi.org/10.29202/nvngu/2018-3/6

4. Kuzmenko, S., Kaluzhnyi, Ye., Moldabayev, S., Shustov, O., Adamchuk, A., Toktarov, A. (2019). Optimization of position of the cyclical-and-continuous method complexes when cleaning-up the deep iron ore quarries. Mining of Mineral Deposits, 13(3), 104112. https://doi.org/10.33271/mining13.03.104

5. Rysbekov, K., Huayang, D., Kalybekov, T., Sandybekov, M., Idrissov, K., Zhakypbek, Y., Bakhmagambetova, G. (2019). Application features of the surface laser scanning technology when solving the main tasks of surveying support for reclamation. Mining of Mineral Deposits, 13(3), 40-48. https://doi.org/10.33271/mining13.03.040

6. Poturaev, V.N., Voloshyn, O.I., Ponomarev, B.V. (1989). Vibratsionnopnevmaticheskoye transportirovaniye sypuchikh materialov. Kiev: Naukova dumka

7. Petlovanyi, M., Kuzmenko, O., Lozynskyi, V., Popovych, V., Sai, K., Saik, P. (2019). Review of man-made mineral formations accumulation and prospects of their developing in mining industrial regions in Ukraine. Mining of Mineral Deposits, 13(1), 24-38. https://doi.org/10.33271/mining13.01.024

8. Filonenko, O. (2018). Sustainable development of Ukrainian iron and steel industry enterprises in regards to the bulk manufacturing waste recycling efficiency improvement. Mining of Mineral Deposits, 12(1), 115-122. 
https://doi.org/10.15407/mining12.01.115

9. Semenenko, E.V., Medvedeva, O.A., Kyrychko, S.N., Koval, N.V. (2017). Substantiation of rational parameters and operating modes of a hydrotransport installation during underwater development of placer deposits. Suchasni resursoenerhozberihayuchi tekhnolohiyi hirnychoho vyrobnytstva [Modern resource-saving technologies of mining], 1(19), 43-52

10. Blyuss, B.A., Semenenko, E.V., Medvedeva, O.A. (2017). Methods for managing the parameters of industrial deposits in the storage of dense pulps of enrichment waste. Suchasni resurso-enerhozberihayuchi tekhnolohiyi hirnychoho vyrobnytstva [Modern resource-saving technologies of mining], 2(20), 71-80

11. Semenenko, Ye.V. (2011). Nauchnyie osnovy i tehnologiy gidromehanizatsii otkryitoy razrabotki titan-tsirkonovyih rossyipey. Kiev: Naukova dumka

12. Baranov, Yu.D., Shuryigin, V.D., Blyuss, B.A., Semenenko, Ye.V.(2006). Selection and justification of the parameters of the circulating water supply system of Volnogorsky MMC. Metallurgicheskaya i gornorudnayapromyishlennost, (4), 100 103

13. Smirnov, A.Ya. Evtehov, V.D., Evtehov, E.V. (2014).Geological structure of hematite quartzite deposits in the Krivoy Rog basin. Naukovyi Visnyk Natsionalnoho Hirnychoho Universytetu, (2), 17 - 23

14. Semenenko, E., Nykyforova, N., Tatarko, L. (2014). The method of hydraulic gradient and critical velocity calculation for hydrotransportation of particles with substantially different densities. $15^{\text {th }}$ International Freight Pipeline Society Symposium, Prague. 248 256

15. Olha Medvedieva, Serhiy Kyrychko, Nina Nykyforova, Nataliia Koval (2019). Substantiation of the boundary of the tailings storage core during the storing of the cleaning rejects by hydraulic method. E3S Web of Conferences, 109, 00056. https://doi.org/10.1051/e3sconf/201910900056

16. Semenenko, Ye.V., Medvedeva, O.A., Kyrychko, S.N., Nykyforova, N.A. (2018). Calculation of parameters and modes of hydrotransport during the development of manmade deposits in storage facilities for enrichment waste Geotehnicheskaya mehanika [Geo-Technical Mechanics], (142), 91-102 